\title{
Healthy controls have as much bile reflux as gastric ulcer patients
}

\author{
N E SCHINDLBECK, C HEINRICH, F STELLAARD, G PAUMGARTNER, \\ AND S A MÜLLER-LISSNER
}

From the Medizinische Klinik Innenstadt und Medizinische Klinik II Grosshadern, University of Munich, Federal Republic of Germany

SUMmaRY Data on duodenogastric reflux of bile in gastric ulcer are conflicting. We therefore measured intragastric bile acid concentration and its composition from individual bile acids, duodenogastric bile acid reflux rate, gastric emptying rate, and secretion rates of volume and acid in 30 patients with gastric ulcer and in 66 healthy controls, both in the fasting state and after feeding a liquid meal. Patients had higher gastric bile acid concentrations $(p<0.05)$ than controls in the fasting state, but the overlap between the groups was considerable. In fasting patients with corpus ulcer, gastric secretion rates were significantly decreased when compared with controls. There was no difference between patients and controls with respect to gastric emptying rate, bile acid reflux rate, intragastric amount of bile acids, and bile acid composition in the fasting state. Postprandially, all parameters tested were similar in patients and controls. Controls showed high reflux rates with similar frequency as did ulcer patients. We conclude that increased gastric bile acid concentrations in the fasting stomach of patients with gastric ulcer are the result of gastric hyposecretion and not of increased reflux. They probably are pathogenetically irrelevant.

Gastric bile acid concentration has been reported to be increased in patients with gastric ulcer ${ }^{1.7}$ When the pyloric pressure in patients with gastric ulcer was measured a lack of response to duodenal acidification was seen. As pyloric pressure has been considered to be involved in the prevention of reflux, duodenogastric reflux has, on the basis of these results, been claimed to be increased and to play a major pathogenetic role in gastric ulcer..$^{1.7}$ We have, however, previously shown that fractional duodenogastric reflux is similar in controls and in gastric ulcer patients."' In order to solve these discrepancies, the present study was designed to evaluate simultaneously bile reflux rates, gastric emptying and secretion rates, and gastric bile acid concentrations in reasonably large samples of gastric ulcer patients and healthy controls.

Address for correspondence: Dr N Schindlbeck, Medizinische Klinik Innenstadt der Universität München, Ziemssenstrasse 1 , D-8000) München 2, Federal Republic of Germany.

Received for publication 21 May 1987.

\section{Methods}

PATIENTS

Thirty patients ( 16 men and 14 women) between the ages of 24 and 85 years with a mean of 55.5 years were included in the study. All patients had endoscopically diagnosed gastric ulcer. In 19 patients the ulcer was located at, or proximal to, the incisura angularis (type I gastric ulcer according to Johnson," subsequently referred to as 'corpus ulcer') and in 11 patients the ulcer was located $3 \mathrm{~cm}$ or less proximal to the pylorus (type III gastric ulcer according to Johnson," subsequently referred to as "pyloric ulcer'). In none of the patients was malignancy suspected on the basis of macroscopical or histological findings. No patient had undergone previous cholecystectomy, gastric resection, or selective proximal vagotomy.

CONTROLS

The control group consisted of 66 healthy volunteers (41 men and 25 women, $20-59$ years, mean $26 \cdot 3$ 
years). None of the controls had any history, symptoms, or signs of digestive tract disease, particularly previous peptic ulcer or biliary disease. The study protocol was approved by the local ethical committee and informed consent was obtained from patients and controls.

\section{EXPERIMENTAI. PROCEDURE}

Experiments were started at 830 am after an overnight fast. A nasogastric tube with an air vent (Salem sump tube, Ch 14) was positioned with its tip in the most dependent part of the stomach under fluoroscopic control. The subject was then laying prone in the left lateral position. Fifteen minutes were allowed for the subject to get accustomed to the tube. Then the gastric contents were aspirated completely. The volume was measured by differential weighing in preweighed glass containers and an equal volume of marker solution consisting of polyethylene glycol 4000 (PEG) $1 \%$ in normal saline was instilled into the stomach. The time between the beginning of aspiration and the end of instillation was three minutes. Twenty seven minutes later the following procedure was carried out within a time span of three minutes: the stomach was first evacuated with a syringe, the volume of the aspirate was measured, and after thorough mixing a $5 \mathrm{ml}$ sample was taken. Five millilitres of marker solution (PEG $5 \%$ in saline) were then added and mixed with the gastric juice. The mixture was reinstilled into the stomach. This procedure was repeated every 30 minutes over a period of two hours.

In 40 of the controls and 18 of the gastric ulcer patients a liquid test meal was instilled into the stomach immediately thereafter. It consisted of $89 \mathrm{~g}$ of Biosorbin ${ }^{\mathrm{R}}$ MCT (Pfrimmer, Germany) made up to $350 \mathrm{ml}$ with tap water. This amount of Biosorbin contains $49.1 \mathrm{~g}$ of carbohydrate, $19.7 \mathrm{~g}$ of protein, and $13.2 \mathrm{~g}$ of fat predominantly in the form of medium chain length triglycerides; it has $400 \mathrm{kCal}$. The test meal was labelled with $100 \mathrm{mg} / \mathrm{l}$ of phenol red. It had an osmolality of $280 \mathrm{mosm} / \mathrm{l}$. One hour after instillation of the test meal the stomach was evacuated, the recovered volume was measured, and samples were taken for subsequent analysis. No subject gagged or experienced nausea during the study.

\section{ASSAY PROCEDURES}

The concentrations of acid, PEG, ${ }^{12}$ phenol red, and total bile acids $^{13}$ were measured in all samples. Mixtures of $1 \mathrm{ml}$ aliquots of all fasting samples were analysed after ultracentrifugation $(20000 \mathrm{~g}$ for 30 minutes at $4^{\circ} \mathrm{C}$ ) for the fractions of total soluble bile acids and, in addition, by gas liquid chromatography for individual bile acids and their conjugates as described below. Postprandial samples were analysed after ultracentrifugation for the fractions of total soluble bile acids.

SAMPLE PREPARATION FOR THE FRACTIONATION OF BILE ACIDS

After thorough mixing, $1 \mathrm{ml}$ gastric juice was diluted with $8 \mathrm{ml} 0 \cdot 1 \mathrm{~N} \mathrm{NaOH}$. Bile acids were extracted by passing this solution through a $100 \mathrm{mg}$ Bond Elute ${ }^{\mathrm{IM}}$ $\mathrm{C}_{18}$ cartridge (Analytichem Int, Harbor City, USA). After rinsing the cartridge with $0 \cdot 1 \mathrm{~N} \mathrm{NaOH}$ and water, bile acids were eluted with $6 \mathrm{ml} 75 \%$ methanol. ${ }^{1+}$ This eluate was passed directly through a $40 \times 8 \mathrm{~mm}$ SP-Sephadex cation exchanger (Pharmacia, Uppsala Sweden) and a $40 \times 8 \mathrm{~mm}$ DEAP-LH-20 anion-exchange column (Packard Instr, Groningen, The Netherlands). After rinsing this last column with $9 \mathrm{ml} 72 \%$ ethanol, the following groups of bile acids were eluted..$^{15}$ The unconjugated bile acids were eluted with $6.5 \mathrm{ml} 0.1 \mathrm{~mol} / \mathrm{l}$ acetic acid in $72 \%$ ethanol at $\mathrm{pH} 4.0$, the glycine conjugated bile acids with $6.5 \mathrm{ml} 0.3 \mathrm{~mol} / \mathrm{l}$ acetic acid in $72 \%$ ethanol at $\mathrm{pH} 5 \cdot 0$, and the taurine conjugated bile acids with $6.5 \mathrm{ml} 0.15 \mathrm{~mol} / \mathrm{l}$ acetic acid in $72 \%$ ethanol at $\mathrm{pH} 6.6$. The $\mathrm{pH}$ was adjusted with concentrated ammonia. Sulphated bile acids were discarded. After evaporation of the eluate, unconjugated bile acids were methylated according to Ali and Javitt ${ }^{\text {th }}$ and converted to methyl ester-trimethylsilyl according to Setchell et al. ${ }^{15}$ Glycine and taurine conjugates were hydrolysed enzymatically ${ }^{17}$ and the free acids reextracted using $40 \times 8 \mathrm{~mm}$ Lipidex 1000 columns (Packard Instr, Groningen, The Netherlands). ${ }^{\text {is }}$ Finally the methyl ester TMS-ether derivatives were formed as described above and dissolved in $1 \mathrm{ml}$ iso-octane. To each of the elution volumes $255 \mathrm{nmol}$ hydeoxycholic acid was added as internal standard before evaporation and further processing.

\section{GAS CHROMATOGRAPHY}

The bile acid methyl ester TMS-ether derivatives were separated on a fused silica $25 \mathrm{~m} \times(0.32 \mathrm{~mm}$ OV-1701 column (CPSil 19 CB, Chrompack, Middelburg, The Netherlands) after injection by cold on-column technique. ${ }^{14}$ Bile acids were quantified using hyodeoxycholic acid as internal standard. Hydrogen was used as carrier gas $\left(0.7 \mathrm{~kg} / \mathrm{cm}^{2}\right)$. The sample was injected at $140^{\circ} \mathrm{C}$, keeping the column at this temperature for one minute. Then the temperature was raised from $140^{\circ}$ to $270^{\circ} \mathrm{C}$ with a slope of $10 \% \mathrm{~min}$. The bile acid derivatives were eluted at $270^{\circ} \mathrm{C}$ and detected with a flame ionisation detector at $290^{\circ} \mathrm{C}$.

CALCULATIONS

Fractional gastric emptying, gastric volume and acid 
secretion, and bile acid reflux were calculated using exponential equations yielding rates in terms of one per minute as follows. The intragastric amount of PEG, acid and bile salts, respectively, at a given time is the product of their concentrations and the measured gastric volume at this time. The change of the intragastric amount G of PEG over time is (1) $\mathrm{dG} / \mathrm{dt}=-\mathrm{gG}$, where $\mathrm{g}$ is the fractional gastric emptying rate. ${ }^{1 *}$ The solution of the equation is (2) $G_{2}=G_{1} e^{-g t}$, where the indices 1 and 2 refer to the beginning and the end of the time interval $t$. The change of the other intragastric quantities over time is given by the equation ( 3 ) $\mathrm{dA} / \mathrm{dt}=-\mathrm{gA}+\mathrm{a}$, where A represents the intragastric amount of fluid secreted by the stomach, acid, and bile salts, respectively, and a represents the rate by which $A$ enters the stomach - that is, secretion rates of volume and acid, respectively, and bile salt reflux rate. The solution of this equation is

$$
\text { (4) } \mathrm{a}=\frac{\left(\mathrm{A}_{2}-\mathrm{A}_{1} \mathrm{e}^{-\mathrm{gt}}\right) \mathrm{g}}{1-\mathrm{e}^{-\mathrm{gt}}}
$$

In our experimental procedure we selected 30 and 60 min periods for the time interval $t$. Thus, when applying the formulas (2) and (4) to our data, the gastric emptying rate $g$ and the secretion and reflux rates $A$ represent the average values of 30 or $60 \mathrm{~min}$, respectively. Appropriate corrections were made for acid and bile acids lost by the sampling procedure. Because the duodenal concentrations of bile acids and bicarbonate were not known, the duodenogastric reflux rates of volume and bicarbonate could not be calculated. The gastric volume secretion rate hence included volume refluxed from the duodenum, which was one order of magnitude smaller than gastric volume secretion. Conversely, the measured acid secretion rate was lowered by refluxed bicarbonate. Very high reflux rates thus would result in apparently higher gastric volume secretion, but in apparently lower acid secretion. The completeness of the gastric aspiration has been validated previously. ${ }^{19}$

\section{STATISTICAL ANALYSIS}

Individual means were calculated for the 30 minute fractions in the fasting periods. Group means were given with SEM. In case of data not normally distributed medians and ranges were used. Statistical comparisons were made with the Wilcoxon's rank-sum test for unpaired data in combination with Bonferroni-Holm's rejective multiple test procedure. ${ }^{20}$

\section{Results}

Data of gastric bile acid concentrations and reflux

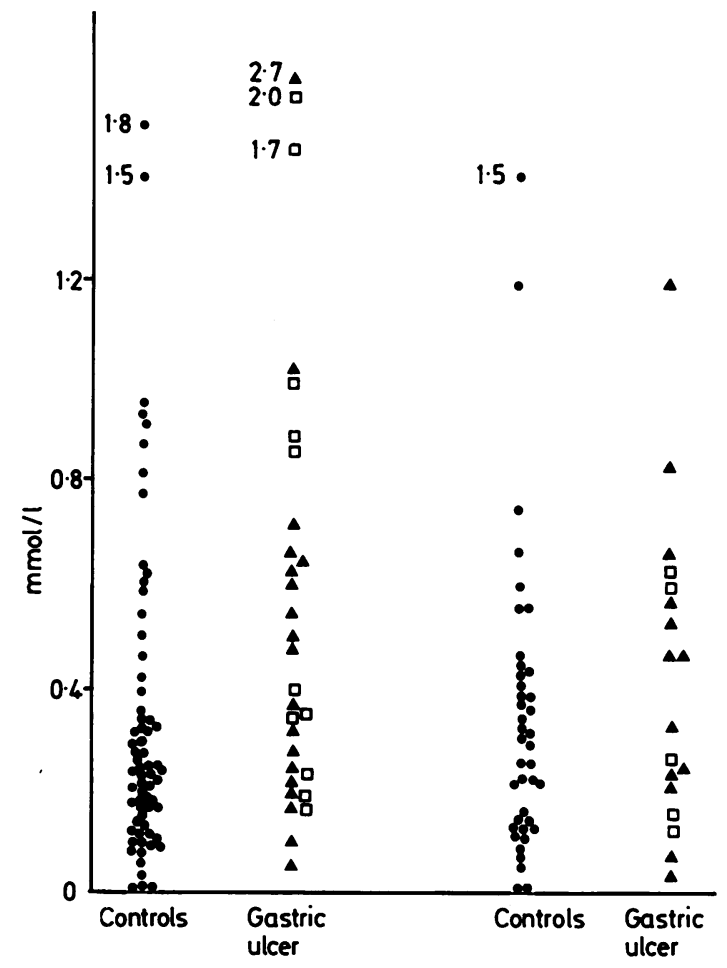

Fig. 1 Gastric bile concentrations in controls and gastric ulcer patients in the fasting state (left panel) and postprandially (right panel). Each point in the fasting state represents the individual mean of four 30 min periods. $\triangle$ represent patients with corpus ulcer, $\square$ represent patients with pyloric ulcer.

rates were markedly skewed in all groups. High values were seen in similar proportions of patients and controls (Figs 1, 2). In the fasting state, patients with both types of ulcer had significantly higher total bile acid concentrations in gastric aspirates than controls (Table, Fig. 1). The reflux rate and the total amount of intragastric bile acids, however, were similar in all groups (Table, Fig. 2). Secretion rates of volume and acid were decreased in patients, but the difference was only significant in patients with corpus ulcer (Table). A trend to lower gastric emptying rates in patients was statistically not significant (Table). The soluble fraction of bile acids was similar in patients and controls (Table). There was no difference in gastric bile acid composition between patients and controls in the fasting state (Fig. 3).

Instillation of the test meal slowed gastric emptying and increased secretion rates of volume and acid, and reflux rate in all subjects (Table). There was no difference between patients and controls postprandially with respect to any of the parameters tested. 


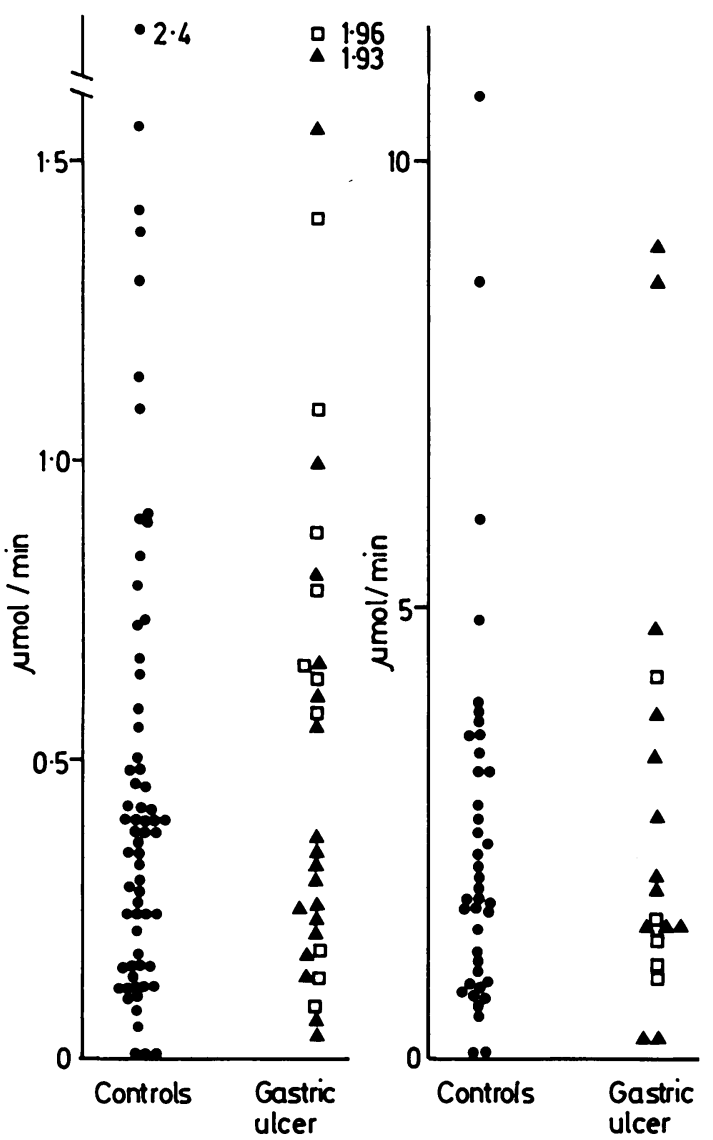

Fig. 2 Bile acid reflux rates in controls and gastric ulcer patients in the fasting state (left panel) and postprandially (right panel). Each point in the fasting state represents the individual mean of four 30 min periods. $\triangle$ represent patients with corpus ulcer, $\square$ represent patients with pyloric ulcer.

\section{Discussion}

The present study confirms the findings of other authors ${ }^{2+6}$ that patients with gastric ulcer have higher bile acid concentrations in the fasting stomach than healthy controls. Most of the investigators explained this finding by increased duodenogastric reflux, although none of them really measured reflux rates. The concentration of bile acids in the stomach does not only depend on reflux of duodenal contents, but also on other factors, such as emptying rate and volume secretion rate of the stomach. We therefore used a method which simultaneously evaluates all three parameters that influence gastric bile acid concentrations in both the fasting and the postprandial state. In our study fasting patients with corpus ulcer had similar bile acid reflux rates,

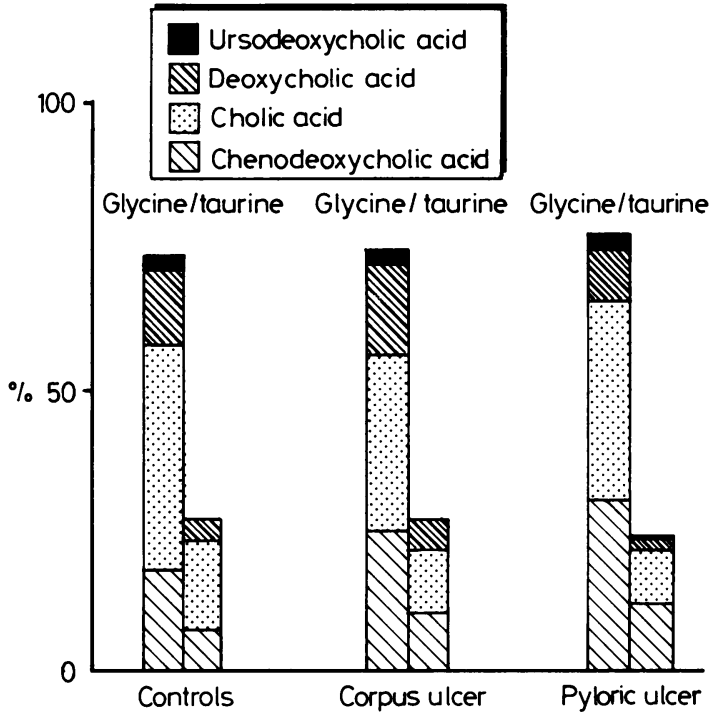

Fig. 3 Percentage composition of individual bile acids and their conjugates of fasting gastric bile acids in controls and gastric ulcer patients (means). Left bars represent glycine conjugated bile acids, right bars represent taurine conjugated bile acids. Unconjugated bile acids were found in two controls and two patients in negligible amounts. Lithocholic acid was found in one control and one patient in negligible amounts.

intragastric amounts of bile acids, and gastric emptying rates as healthy controls. In contrast, the secretion rates of volume and acid were decreased in patients with corpus ulcer. Thus, our data clearly show that higher gastric bile acid concentrations in fasting patients with corpus ulcer are caused by gastric hyposecretion and not by increased reflux rates. In patients with pyloric ulcer we observed a trend to lower secretion rates of volume, to higher bile acid reflux rates, and to higher intragastric amounts of bile acids, but the differences were not statistically significant. Probably both mechanisms, namely lower gastric secretion and higher bile reflux rates, act in combination and thus result in higher gastric bile acid concentrations.

Patients with gastric ulcer have also been reported to have higher postprandial gastric bile acid concentrations than healthy controls. ${ }^{1.5}$ In analogy to fasting studies these findings were ascribed to an increase of duodenogastric reflux. Some evidence for hyposecretion of volume in gastric ulcer patients was, however, also found. ${ }^{3}$ We failed to confirm the observations made by other authors with respect to the postprandial state. Patients in our study had similar bile acid concentrations, reflux rates, and secretion rates as controls. Some methodological 
Table Experimental results in patients and controls.

\begin{tabular}{|c|c|c|c|}
\hline Fasting & $\begin{array}{c}\text { Controls } \\
\text { (66) }\end{array}$ & $\begin{array}{l}\text { Corpus ulcer } \\
\text { (19) }\end{array}$ & $\begin{array}{l}\text { Pyloric ulcer } \\
\text { (11) }\end{array}$ \\
\hline Gastric emptying rate (\%/min) & $5 \cdot 1 \pm 0 \cdot 3$ & $4 \cdot 2 \pm 0 \cdot 3$ & $4 \cdot 2 \pm 0 \cdot 2$ \\
\hline Secretion ratc of volume $(\mathrm{ml} / \mathrm{min})$ & $1 \cdot 5 \pm 0 \cdot 1$ & $0.9 \pm 0 \cdot 1 \dagger$ & $1 \cdot 2 \pm 0 \cdot 2$ \\
\hline Secretion ratc of acid $(\mu \mathrm{mol} / \mathrm{min})$ & $60) \pm 7$ & $33 \pm 7^{*}$ & $51 \pm 14$ \\
\hline Reflux rate $(\mu \mathrm{mol} / \mathrm{min})$ & $0 \cdot 37(0 \cdot 00-2 \cdot 40)$ & $0 \cdot 34(0 \cdot 02-1 \cdot 93)$ & $0 \cdot 65(0 \cdot 08-1 \cdot 96)$ \\
\hline Intragastric amount of bilc acids ( $\mu \mathrm{mol})$ & $6.9(0 \cdot 1-59 \cdot 8)$ & $7 \cdot 3(1 \cdot 2-37 \cdot 3)$ & $17 \cdot 1(2 \cdot 0-47 \cdot 0)$ \\
\hline Total bile acid concentrations ( $\mathrm{mmol} / \mathrm{l})$ & $0 \cdot 24(0 \cdot 00-1 \cdot 80)$ & $0 \cdot 48\left(0 \cdot 06-2 \cdot 7(0)^{*}\right.$ & $0.39(0 \cdot 17-2 \cdot 00)^{*}$ \\
\hline Fraction of soluble bilc acids ( $\%)$ & $58 \pm 6$ & $59 \pm 5$ & $63 \pm 6$ \\
\hline Postprandial & $\begin{array}{l}\text { Controls } \\
\text { (40) }\end{array}$ & $\begin{array}{l}\text { Corpus ulcer } \\
\text { (I3) }\end{array}$ & $\begin{array}{l}\text { Pyloric ulcer } \\
\text { (5) }\end{array}$ \\
\hline Gastric emptying rate (\%/min) & $1 \cdot 3 \pm 0 \cdot 1$ & $1 \cdot 3 \pm 0 \cdot 2$ & $1 \cdot 1 \pm 0 \cdot 2$ \\
\hline Secretion rate of volume $(\mathrm{ml} / \mathrm{min})$ & $3 \cdot 1 \pm 0 \cdot 2$ & $2 \cdot 7 \pm 0 \cdot 5$ & $2 \cdot 8 \pm 0 \cdot 6$ \\
\hline Secretion rate of acid $(\mu \mathrm{mol} / \mathrm{min})$ & $209 \pm 18$ & $163 \pm 34$ & $186 \pm 45$ \\
\hline Reflux rate $(\mu \mathrm{mol} / \mathrm{min})$ & $1 \cdot 9(0 \cdot 0-10 \cdot 7)$ & $2 \cdot 0(0 \cdot 2-9 \cdot 1)$ & $1 \cdot 5(0 \cdot 9-4 \cdot 2)$ \\
\hline Intragastric amount of bile acids $(\mu \mathrm{mol})$ & $71 \cdot 4(0 \cdot() 3-597 \cdot 2)$ & $88 \cdot 5(10 \cdot 8-416 \cdot 2)$ & $84 \cdot 0(48 \cdot 5-169 \cdot 6)$ \\
\hline Total bile acid concentrations $(\mathrm{mmol} / \mathrm{l})$ & $0 \cdot 31(0 \cdot 00-1 \cdot 50)$ & $0 \cdot 47(0 \cdot(04-1 \cdot 19)$ & $0 \cdot 26(0 \cdot 13-0 \cdot 63)$ \\
\hline Fraction of soluble bile acids $(\%)$ & $60 \pm 9$ & $78 \pm 15$ & $62 \pm 21$ \\
\hline
\end{tabular}

Means \pm SEM, medians (ranges), ${ }^{*} / \dagger=p<0 \cdot 05 / 0 \cdot 01$ when compared with controls

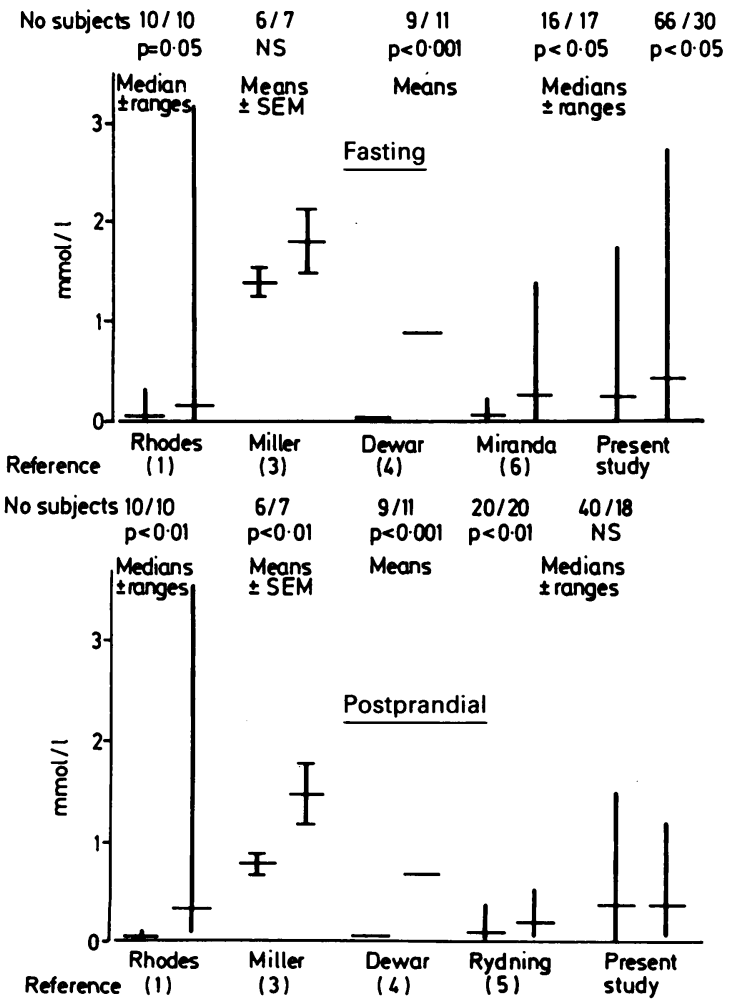

Fig. 4 Gastric bile acid concentrations in studies of other authors and in the present study (left bars represent controls, right bars represent gastric ulcer patients). Extraction of the appropriate data (that is, medians and ranges, was not possible from all references; $p$ values in the cited studies are not adjusted for multiple comparisons. differences - for example liquid or solid meal, instillation or ingestion of the meal may partly explain diverging results in the different studies.

The most obvious difference between our results and those of others is the frequent finding of considerable bile acid concentrations not only in the patient's but also in the control group, both in the fasting state and postprandially. This is illustrated in Figure 4. We are unable to explain why controls in other studies were more or less free of bile reflux. One reason may be the small number of subjects studied. We consider it unlikely that our method of collecting gastric samples might explain this difference. Previous work from our laboratory"1 shows that the conventional way to collect gastric juice, namely continuous aspiration, yields higher reflux rates than the marker solution technique applied in the present study. Thus, the difference in the experimental design could explain lower, but not higher bile concentrations in comparison with other authors results. ${ }^{36}$ As only soluble bile acids are likely to damage the gastric mucosa ${ }^{22}$ and because the individual bile acids are not equally damaging ${ }^{23}$ we wondered whether gastric ulcer patients would for whatever reason differ from controls in respect to their bile acid composition. This is clearly not the case.

Irrespective of the cause of the small increase in fasting gastric bile acid concentration of gastric ulcer patients, namely motility disorder or reduced volume secretion, one may argue that it could nevertheless be pathogenetically relevant in gastric ulcer. Although the difference of gastric bile acid concentrations between controls and patients is statistically significant, the overlap between the groups is very 
large. It seems rather unlikely, therefore, that this difference could be clinically relevant. Furthermore, if the above hypothesis were true, a high gastric ulcer prevalence would be expected in conditions with excessive reflux, such as after Billroth I and II gastric resection. The very high gastric bile acid concentrations in these patients ${ }^{2+}$ may cause the socalled bilious gastritis, ${ }^{25}$ but ulcers in the gastric stump are found only in a minority of patients with the postgastrectomy syndromes. ${ }^{2027}$ Further, cholecystectomy leads to increased gastric bile acid concentrations in the fasting state. ${ }^{2 x}$ In two epidemiologic studies, however, no increased coincidence of gastric ulcer and previous cholecystectomy was found. ${ }^{31.31}$ This provides further evidence against a pathogenic role of reflux or high gastric concentrations of bile acids for gastric ulcer.

In conclusion, our study shows that healthy subjects and gastric ulcer patients have similar bile reflux rates and that increased bile acid concentrations in the fasting stomach of patients with gastric ulcer are caused by gastric hyposecretion and not by increased reflux. Circumstantial evidence argues against a role of high bile acid concentrations in the pathogenesis of gastric ulcer. This does not exclude, however, the possibility that withholding bile from the stomach could speed gastric ulcer healing, in analogy to the ulcer healing achieved by blocking acid secretion despite normal or reduced secretion in patients with gastric ulcer.

This study was supported by Deutsche Forschungsgemeinschaft DFG (Mu 629/1-5). Norbert Schindlbeck is recipient of a grant of Deutsche Forschungsgemeinschaft DFG (Mu 629/1-5).

\section{References}

1 Rhodes J, Bernardo DE, Phillips SF, Rovelstad RA, Hofmann AF. Increased reflux of bile into the stomach in patients with gastric ulcer. Gastroenterology 1969; 57: 241-52.

2 Black RB, Roberts G, Rhodes J. The effect of healing on bile reflux in gastric ulcer. Gut $1971 ; 12$ : 552-8.

3 Miller LJ, Malagelada JR, Lonstreth GF, et al. Dysfunction of the stomach with gastric ulceration. Dig Dis Sci 1980; 25: 857-64.

4 Dewar EP, King RFG, Johnston D. Bile acid and lysolecithin concentrations in the stomach of patients with gastric ulcer: before operation and after treatment by highly selective vagotomy, Billroth I partial gastrectomy and truncal vagotomy and pyloroplasty. Br J Surg 1983; 70: 401-5.

5 Rydning A, Berstad A. Intragastric bile acid concentrations in healthy subjects and in patients with gastric and duodenal ulcer and the influence of fiber-enriched wheat bran in patients with gastric ulcer. Scand $J$ Gastroenterol 1985; 20: 801-4.
6 Miranda M, Defillippi C, Valenzuela JE. Abnormalities of interdigestive motility complex and increased duodenogastric reflux in gastric ulcer patients. Dig Dis Sci 1985; 30: 16-21.

7 Gotthard R, Bodemar G, Tjädermo M, et al. High gastric bile acid concentration in prepyloric ulcer patients. Scand J Gastroenterol 1985; 20: 439-46.

8 Fisher RS, Cohen S. Pyloric-sphincter dysfunction in patients with gastric ulcer. NEnglJ Med 1973;288: 273-6.

9 Fisher RS, Boden G. Reversibility of pyloric sphincter dysfunction in gastric ulcer. Gastroenterology 1975; 69: 591-7.

10 Müller-Lissner SA. Fimmel CJ, Sonnenberg A, et al. Novel approach to quantify duodenogastric reflux in healthy volunteers and in patients with type I gastric ulcer. Gut 1983; 24: 510-8.

11 Johnson HD. Gastric ulcer: classification, blood group characteristics, secretion patterns and pathogenesis. Ann Surg 1965; 162: 999-1004.

12 Buxton TB, Crockett JK, Moore WL, Moore WL Jr, Rissing JP. Protein precipitation by acetone for the analysis of polyethlene glycol (PEG). Gastroenterology 1980; 79: 35-9.

13 Talalay P. Enzymatic analysis of steroid hormones. Methods Biochem Anal 1960; 8: 119-43.

14 Stellaard F, Sackmann M, Sauerbruch T, Paumgartner G. Simultaneous determination of cholic and chenodeoxycholic acid pool sizes and fractional turnover rates in human serum using ${ }^{1.3} \mathrm{C}$-labeled bile acids. J Lipid Res 1984; 25: 1313-9.

15 Setchell KDR, Matsui A. Serum bile acid analysis. Clin Chim Acta 1983; 127: 1-17.

16 Ali SS, Javitt NB. Quantitative estimation of bile salts in serum. Can J Biochem 1970; 48: 164-71.

17 Karlaganis G, Paumgartner G. Determination of bile acids in serum by capillary gas-liquid chromatography. Clin Chim Acta 1979; 92: 19-26.

18 Müller-Lissner SA, Fraass C, Härtl A. Cisapride offsets dopamine-induced slowing of fasting gastric emptying. Dig Dis Sci 1986; 31: 807-10.

19 Müller-Lissner SA, Fraass C. Dissociation of duodenogastric marker reflux and bile salt reflux. Dig Dis Sci 1985; 30: 733-8.

20 Holm S. A simple sequentially rejective multiple procedure. Scand J Statist 1979; 6: 65-70.

21 Müller-Lissner SA, Fraass Ch. Measurements of bile salt reflux are influenced by the method of collecting gastric juice. Gastroenterology 1985; 89: 1338-41.

22 Duane WC, Wiegand DM. Mechanism by which bile disrupts the gastric mucosa barrier in the dog. J Clin Invest 1980; 66: 1044-9.

23 Ritchie WP, Felger TS. Differing ulcerogenic potential of dihydroxy and trihydroxy bile acids in canine gastric mucosa. Surgery 1981; 89: 342-7.

24 Duane WC, Wiegand DM, Gilberstedt ML. Intragastric duodenal lipids in the absense of a pyloric sphincter: quantitation, physical state, and injurious potential in the fasting and postprandial states. Gastroenterology 1980; 78: 1480-7.

25 Meshkinpour H, Marks JW, Schoenfield LJ, Bonnoris GG, Carter S. Reflux gastritis syndrome: mechanisms of symptoms. Gastroenterology 1980; 79: 1283-7. 
26 Alexander-Williams J, Wolverson RL. Pathogenesis and pathophysiology of gastric ulcer. Clin Gastroenterol 1984; 13: 601-19.

27 Kelly KA, Malagelada JR. Medical and surgical treatment of chronic gastric ulcer. Clin Gastroenterol 1984; 13: 621-34.

28 Müller-Lissner SA, Schindlbeck NE, Heinrich Ch. Bile salt reflux after cholecystectomy. Scand J Gastroenterol 1987 (in press).
29 Svensson JO, Gelin J, Svanik J. Gallstones, cholecystectomy, and duodenogastric reflux of bile acid. Scand J Gastroenterol 1986; 21: 181-7.

30 Lee SP. The stomach after cholecystectomy. Am J Surg 1983; 145: 325.

31 Miller LJ, Resseguie LJ, Taylor WF, Malagelada JR. Cholecystectomy and gastric ulcer - an etiologic relationship ? Mayo Clin Proc 1980; 55: 255. 